\title{
Frequency of Pulmonary Mycobacterium Tuberculosis among Patients of Civil Hospital New Darband
}

\author{
Shah Zeb*, Noorullah \\ Faculty of Health Sciences, Department of Microbiology, Hazara University Mansehra, Khyber Pakhtunkhwa, Pakistan.
}

\begin{abstract}
Objective: The contemporary study conceded out on distribution of Mycobacterium tuberculosis in civil hospital new Darband and its rural areas such as Serri, Shanayia, Sookal, Baghwai and Nika paani. During directing research work the information and data was placid from several villages including new Darband. This demonstrates higher indication of tuberculosis in female as compared to males hence high-risk of disease in females is due to their neighboring contact, poor sanitation, and lack of health education, poor-hygiene and lack of awareness.
\end{abstract}

Methods: During research work Cross sectional study was conducted in civil hospital new Darband during the months of calendar from May to October. All patients were cross-examined by using paper questionnaire comprised questions about the socio-economics, demographic such as Age, gender and area (where they were belonging), previous family tuberculosis history and others while they were examined clinically by qualified medical officer. Additionally ICT serological testation was used to conform the suspected agents which were done by the average blood serum. They were studied further to conform their suspicions in sputum by applying Ziehl-Neelson staining method to investigate the AFB (Acid Fast Bacilli) in sputum smear which was carried-out in hospital laboratory. AFB (Acid Fast Bacilli) smears were introduced to microscopic examination for fluorochrome stain of specimen.

Results: 15 were positive cases out of 374 cases. Greater Incidence of tuberculosis was testified in Sookal $5(8.33 \%)$ while minimum frequency of tuberculosis was demonstrated in Tehsil New Darband $0(0 \%)$. In Gender wise prevalence in which 15 positive cases of tuberculosis $4(2.42 \%)$ were male while $11(5.26 \%)$ were female. The risk of mycobacterium tuberculosis were established in population of intermediate age people such as $14-40$ years (4.54\%) although less risk of disease are originated in the children and risk in adult was (2.22\%). In calendar of month-wise prevalence the month of October (7.69\%) was documented for higher cases Instead of July. In July rare or non-cases are reported mean $(0 \%)$.

Conclusion: For the incidence of TB poverty, poor cleanliness, absence of schooling, less viability of medications and additionally poor pharmaceutical indicating major elements. The TB control program will be effective, convenience to treatment centers and health education, well qualified and active persons are provided, and program must be for gigantic duration. Because well-trained microbiologist can be execute sputum Acid fast staining technique very accurately instead of non-concern partitions. Hence, such thoughtful research work assumes can play vital role for the control of TB in Pakistan, especially in New Darband and its ruler areas that are under review.

Keywords: Mycobacterium tuberculosis, Acid-fast-bacilli, Acid fast staining, ICT serological testation, Mortality, Chest pain.

\section{INTRODUCTION}

"Mycobacterium tuberculosis is responsible to cause tuberculosis that reported as threat foremost to extraordinary morbidity and mortality around the world. TB is powerful reason to cause lung diseases through-out the world as compare to other infectious diseases [1]. Tuberculosis is highly dynamic infection that affects lungs in 77\% cases such as pulmonary tuberculosis while $23 \%$ cases effect presents extra-pulmonary tuberculosis. TB is characterized by coughing chest-ache, fever and weight loss as exposed to several environmental circumstances during infection which depend on the risk of sickness. In expose candidate Organism replicates in macrophages and used as shelter. While in exposed lung cavities they are multiply in extra-cellular which found in late phase of the disease [2]. Mycobacterium

*Address correspondence to this author at the Faculty of Health Sciences, Department of Microbiology, Hazara University Mansehra, Khyber Pakhtunkhwa, Pakistan. E-mail: microbiologist018@gmail.com tuberculosis spreading in human population since ancients. Initially, 12,000-17,000 cases of tuberculosis were report, few years ago [3]. Nonetheless, in century 17th anatomical and physiological reports of TB (tuberculosis) were started [4]. As evaluated $33 \%$ population of the world get infections of Mycobacterium tuberculosis, displaying key obstruction.

When the WHO (World Health Organization) proclaimed tuberculosis throughout the world health emergency in (1992) tuberculosis were succeeded in virtually altogether countries of the world. Even with, the fast endeavors control of disease was a considerable duration and remained the 7 th energetic reason for death around the globe [5]. WHO calculated $(9.37$ million) newly identified cases globally in 2008 while in $>90 \%$ developing countries ( 1.5 million) deaths were reported (WHO, 2008). Although 97\% of tuberculosis cases occur in high-endemic countries, thus, disease remains a major issue in industrialized countries, mostly in the refugee population. In 
elder or aged people with reactivating inert infection in local outbreaks [6]. In (2015), about 9.8 million suffered from tuberculosis in which 1.6 million passed away via such disease while most of them 970 deaths reported in low or middle income countries, particularly, 5 deaths reported in age 15 to 44 years. For the year 2014, approximately, 1 million children meet with tuberculosis in which 140,000 children's died. In 2015, Tuberculosis was reported as a frequent cause of deaths in HIV positive population about 1 in 3 deaths were reported in tuberculosis suffered individuals. TB rate has been dropped by an average of $1.5 \%$ year since 2000 while currently $23 \%$ lower instead previous.

WHO recorded 3.8 million new occurrences of tuberculosis in the year 2010 and 2015, respectively, in which $90 \%$ occur in developing countries while, 8.6 million new cases have been reported worldwide [7]. In (2010), 92\% of cases reported in developed countries of Asia (6 million) Africa ( 3 million), Middle East ( 7 million), and Latin America (0.5 million). It has been also estimated that in (2015) 1.9 million deaths occurred from tuberculosis about $97 \%$ of them in developing countries [8]. Mycobacterium tuberculosis can be spread fluently from patient to healthy individual by droplet having nuclei which are aerosolized by coughing, sneezing or talking. Aerosols are dried quickly; the smallest ( $<10 \mu \mathrm{m}$ in diameter) may stay suspended in the air for few hours or may gain direct access to the terminal air passage as breathed in. droplet comprises about 3,000 infectious nuclei per hack [9]. Pakistan is a $7^{\text {th }}$ most crowded country around the world and second in Islamic countries after Indonesia as the top TB burden country of the world. The episodes of tuberculosis in Pakistan were $241 / 100,000$ in which prevalence and mortality were $320 / 100,000$ and 43/100,000 respectively [10]. By treatments it is insufficient to dispense the TB for many instances of undetected latent TB infection (LTB), over certain duration and can be created as a dynamic disease. For this reason, identifying persons with LTB is essential to the impartial of TB control [11]. In the developing countries like India, have a genuine burden of tuberculosis for centuries.

About 8 million people experience from TB every year. By the speedy transmission of the human immunodeficiency virus (HIV) the issue of tuberculosis became complex [12]. Initial Testation of tuberculosis was developed by Charles Mantoux (Mantoux, 1908) with little infection relatively, and for evaluating the existence of TB it turns into the standard means. Particular test, purified protein derivative (PPD), hundreds antigen mixture is released by Mycobacterium tuberculosis and injected intradermally, after 2-4 days at the site of injection is examined for in duration indicative of prior TB exposure [13]. Though TST is specific technique used for detection of tuberculosis and still it has restrictions concerning exactness and unwavering quality other tests are also utilized for the recognition of this disease like PCR, ICT test performed by Centrifuge the specimen at high-speed and then $10 \mu \mathrm{L}$ of serum was transferred to a specific tube of ICT test while further add 3 drops of buffer solution and kept for 15 minutes. Device comprises two constituents (a) $\mathrm{T}$ line curved dark; it perceived the existence of TB infection while (b) $\mathrm{C}$ present control of particular device while AFB (Acid Fast Bacillus) were performed with Wire loop sputum specimen was isolated and placed on slide to prepare the smear with the support of materials, hence, acid fast stain was continued the progress of specimen followed by carbon Fascine for 5 minutes to settle-down inside the slides and wash with decolorized for about 3 minutes while at the end Methylene blue was added for a minute to examine the slide under microscope using $100 \mathrm{X}$ eyepieces.

\section{DISTRIBUTION OF TUBERCULOSIS IN THE WORLD AND PAKISTAN}

Tuberculosis is considered as major diseases in Asia in the world. Where TB reached (45\%) in the year 2017 to 2018 According to the World Health Organization (WHO) except European and American countries increase its prevalence in the world [14]. A total of 7.8 million cases and 2.7 million deaths were recorded in (2017) globally. The HIV epidemic in which a huge number of Tuberculosis cases are reporting. Specifically, in Africa, although increases are also expected in South East Asia [15]. Tuberculosis (TB) is a major medical issue in Pakistan. TB has been common in Pakistan and sadly it has been one of the ignored health zones previously. Pakistan is leading 8 figures throughout the world nations having a high proportion of Tuberculosis. Pakistan contributes around $47 \%$ of tuberculosis weight in the Eastern Mediterranean Region [16]. It was depicted the study of disease transmission of tuberculosis and evaluated ebb and flow appraisals of tuberculosis contamination and mortality on the planet. In South Africa and Southeast Asia, the most noteworthy predominance of tuberculosis and assessed yearly hazard happen. In 20174.0 million cases were accounted for on the planet out of which $50 \%$ were in Southeast Asia [17].

\section{SYMPTOMOLOGY OF TUBERCULOSIS}

- Symptoms of Tuberculosis are frequently coughing at least three weeks.

- Chest pain.

- Difficulty in breath or coughing.

- Weight loss.

- Fatigue, Fever.

- Night sweats and chills [18].

\section{MATERIALS AND METHODS}

A Cross-sectional study was conducted in civil hospital new darband during the months of the calendar from May to October. All patients were cross-examined by using paper questionnaire comprised questions about the socio-economics, demographics such as age, gender and area (where they were belonging), previous family tuberculosis 
history and others while they were examined clinically by qualified medical officer then 374 blood samples were collected from patients in which 15 patients were positive or suspected as tuberculosis-infected patients. Tuberculosis suspected patients define as individual who present same sign and symptoms such as appearance and characteristics of tuberculosis such as hemoptysis, anorexia, tiredness, evening Pyrexia, chest torment, chest X-ray finding unusual shadows, discomfort, and cavitation's and/or abnormalities in the lymph node, weight-loss, night sweating, high-fever and longer coughing (more than 2-3 weeks). Early morning Sputum was collected from patients in sterile, disposable containers. They were studied further to confirm their suspicions in sputum by applying the Ziehl-Neelson staining method to investigate the AFB (Acid Fast Bacilli) in sputum smear which was carried out in a hospital laboratory. AFB (Acid Fast Bacilli) smears were introduced to microscopic examination for fluorochrome stain of the specimen. Additionally ICT serological testation was used to confirm to the suspected agents who were done by the average blood serum. Culture and Acid-Fast Bacilli (AFB) are two different tests reliably done together in (MSPHL) Tuberculosis Unit. Culture of AFB is the inoculation of a clinical case on culture media (B-D MGIT soup) Becton-Dickinson Mycobacterium Growth Indicator Tube and (L-J) Lowenstein-Jensen media slant, incubating at $37 \mathrm{C}$ up to six (6) weeks. The study was conducted to find-out the prevalence of tuberculosis (TB) in patients of civil hospital new Darband.

Reporting Criteria; Sputum positive smear typical symptoms of tuberculosis with (low-grade fever more than one week), cough (more than four weeks), and chest X-ray screening (cavitary lesions in slightly of the lobes of the lungs) (Table 1) [19].

Table 1. Reporting Criteria for Positive Sputum.

\begin{tabular}{|c|c|}
\hline No. of Organism & Remarks \\
\hline 1-3 bacilli per slide & $(+)$ positive \\
\hline $4-8$ bacilli per slide & $(++)$ positive \\
\hline 9- 10 per slide & $(+++)$ positive \\
\hline Numerous or Per field & $(+++)$ positive \\
\hline Neg (negative) & Not seen \\
\hline
\end{tabular}

\section{RESULTS}

\section{Area-wise Prevalence of Tuberculosis among Civil Hospital New Darband}

80 blood films were gathered from Sheenya in which 4 were positive cases and 76 were negative cases. High occurrence of The TB infection documented in Sookal. 50 blood films were collected from Nika Paani in which 2 were positive cases while 48 were negative cases. 65 blood films were together from Serri in which 1 case of TB positive and 64 were negative samples. From Darband 47 blood films were gathered in which no case is detected thus 47 cases were negative. From bagwai 72 individuals' blood films were collected out of which 3 have TB disease and in 69 individuals no TB infections were found. From Sookal 60 blood films were gathered from individuals in whom 5 indicated TB infection and 55 have no TB infection. During the research, high prevalence tested in Village Sookal which were 8.38\% while 15 samples were positive means has TB infection out of 374 samples total collected (Table 2).

Table 2. Village Wise Frequency Rate of Tuberculosis Infection.

\begin{tabular}{|c|l|c|c|c|c|c|}
\hline $\begin{array}{c}\text { S. } \\
\text { No. }\end{array}$ & $\begin{array}{c}\text { Name } \\
\text { Locality }\end{array}$ & $\begin{array}{c}\text { Number of } \\
\text { Individual }\end{array}$ & $\begin{array}{c}\text { Positive } \\
\text { Cases }\end{array}$ & $\begin{array}{c}\text { Prevalence } \\
\%\end{array}$ & $\begin{array}{c}\text { Negative } \\
\text { Cases }\end{array}$ & $\begin{array}{c}\text { Prevalence } \\
\%\end{array}$ \\
\hline 1 & Sheenaya & 80 & 4 & $5 \%$ & 76 & $95 \%$ \\
\hline 2 & Nika-Paani & 50 & 2 & $4 \%$ & 48 & $96 \%$ \\
\hline 3 & Serri & 65 & 1 & $1.53 \%$ & 64 & $98.46 \%$ \\
\hline 4 & Darband & 47 & 0 & $0 \%$ & 47 & $100 \%$ \\
\hline 5 & Bugwai & 72 & 3 & $4.16 \%$ & 69 & $95.83 \%$ \\
\hline 6 & Sookal & 60 & 5 & $8.33 \%$ & 55 & $91.66 \%$ \\
\hline & Total & 374 & 15 & $4 \%$ & 359 & $95.98 \%$ \\
\hline
\end{tabular}

\section{Sex-wise Distribution of Tuberculosis}

The Sex-wise distribution of Tuberculosis by Gathering of blood films comprises 165 male while 209 female cases to find the agents Mycobacterium tuberculosis. Out of 374 individuals, 15 were positive for Mycobacterium tuberculosis. The Positive case's ratio in males out of 165 blood films was $4(2.42 \%)$ while the female ratio was $11(5.26 \%)$. The female (5.26\%) representing a higher risk of $\mathrm{TB}$ as compared to males $(2.42 \%)$. Reasons for the higher frequency of TB in females were null-care (patient delay), heavier workloads, common prohibition, prioritization of other family members done own prosperity, absence of sovereignty, indifference economic resources and weakness in choice selection. They show postponements for diagnosis and treatment due to domestic activities. They perform fewer activities in outside society and constrained economic resources than men and women bear more loss of income probably because of more lost workdays (Table $\mathbf{3}$ ).

Table 3. Sex-wise Distribution of Tuberculosis among Civil Hospital Patients.

\begin{tabular}{|c|c|c|c|}
\hline Sex & $\begin{array}{c}\text { No. of individual } \\
\text { examined }\end{array}$ & $\begin{array}{c}\text { No. of positive } \\
\text { individuals }\end{array}$ & Prevalence (\%) \\
\hline Male & 165 & 4 & $2.42 \%$ \\
\hline Female & 209 & 11 & $5.26 \%$ \\
\hline Total & 374 & 15 & $4.01 \%$ \\
\hline
\end{tabular}

Age-Wise Prevalence of Tuberculosis among Civil Hospital Patients

Age-Wise prevalence of Tuberculosis among civil hospital patients Middle age peoples were highly suspected of TB. A Total of 220 blood films were examined at the age of 13-40 in which $10(4.45 \%)$ suspected as sick or suffer that shows a 
group at higher risk. 45 blood samples were collected in age 1-12 group children, in which $1(2.22 \%)$ cases were positive. This demonstrated that the TB occurrence is lower in this age, as contrasted with middle age. 109 blood samples were gathered in age $41<$ group while after examination it indicated $4(3.66 \%)$ positive cases. Current research presenting higher TB prevalence occurs in the middle age people as compared to elder or aged and children (Fig. 1).

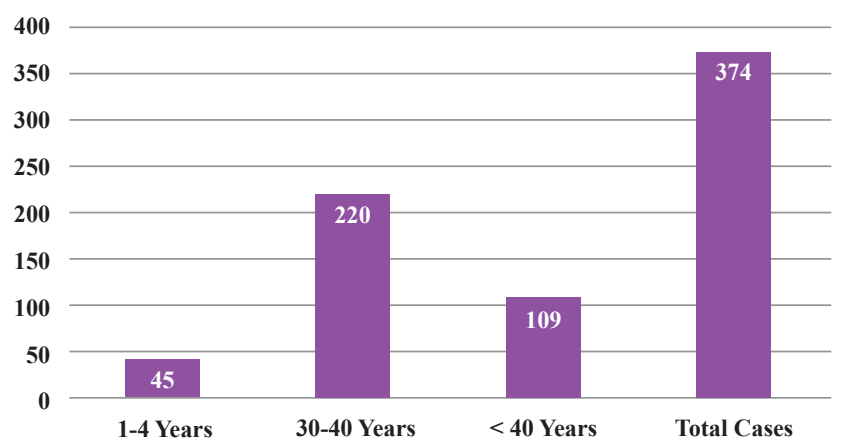

Fig. (1). Age-wise Distribution of Tuberculosis among Civil Hospital Patients.

\section{Month wise Outbreak of TB in among Civil Hospital Patients from May to October.}

Month wise Outbreak of TB among civil hospital patients from May to October. The month-wise dispersion of tuberculosis infection rate highest in October as compared to July due to the lowest infection or cases. In May 47 blood samples were collected in which 1 positive case ratio about $(2.12 \%)$ while In June, a total of 71 blood samples were gathered in which 3 positive case's ratio about $(4.22 \%)$. In July, a total 57 blood samples was collected in which no case of TB appear $0(0 \%)$. In August, total collection of blood samples was 54 in which $4(7.40 \%)$ positive cases. In September, a total of 67 blood samples was collected 1 in which $(1.49 \%)$ infection of tuberculosis found. In October 78 blood samples were collected $6(7.69 \%)$ were positive (Fig. 2).

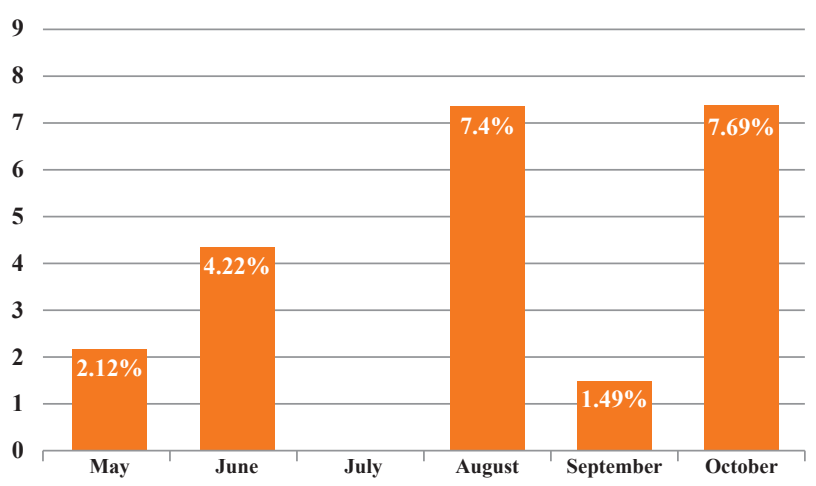

Fig. (2). Month Wise Outbreak of TB in among Civil Hospital Patients from May to October.

\section{DISCUSSION}

This is acknowledged by presenting current research work done that people to live beneath or poverty line such as females get positive cases of tuberculosis found in them hence, they are in threat of tuberculosis infection. Tuberculosis is leading a massive proportion worldwide like infectious disease specifically in developing countries like Pakistan where known as 4th huge cause of death. As indicated by (2017) approximation 182 in 100,000 new cases were reported and 225 in 100,000 major cases in Pakistan [20]. In the country the appreciable technique is controlling TB to aware the population is early diagnosis and viable treatment of active cases due to later diagnosis or ignorance of treatment can be caused positive cases which is the main reason in enhancing hazard as a result it prompts the high ratio of MDR cases in Pakistan. Recently for diagnosis, the developing countries concentrate on AFB stains, culture, and radiographic variation. In this exploration, work is done by 374 patients who had active TB, general population experienced that such infections belong to the middle class. Common symptoms were anemia, had bronchial breathing, during research work the vast majority of individual's specifically female $\mathrm{Hb}$ level was $8-11 \mathrm{gm} / \mathrm{dl}$ and has in reproductive the age between 15 and 29 years, their safety might be traded off. The higher proportion of TB is recorded in female due to null-care (patient delay), because of shame, load of workloads, and social avoidance, prioritization of other family members over claim prosperity, no autonomy, timidity to financial resources and shortcoming in basic leadership; they meet slower supplier, diagnostic and treatment delay, they are hectic in more actions that should be supplanted in the family, further female have more consumption than male, because they require a companion , having less outside activities and financially powerless. The persons related to the age group 15 to 29 years indicating a higher TB ratio due to outside environment activities described by poor sanitation and contaminated actions. The individuals belonging to this age group are mostly in connection with an industrialized environment where they inhale contaminated air and dirt particles which might cause alveolar swelling that leads to resistant suppression, despite the fact of Mycobacterium tuberculosis observed as a human pathogen. It has been frequently reported in household creatures and wild creatures. Generally living in close contact or relationship with people [21-24]. It has been suggested in dairy cattle among local creatures disease with $\mathrm{M}$. tuberculosis recognized [25-27]. As a consequence of the standard tuberculin testing of cows groups disease in steers with Mycobacterium tuberculosis has been recognized [28, 29]. A quick vanishing disease generally created by Mycobacterium tuberculosis in domesticated animals and when these unhygienic creatures tested with tuberculin then they respond decidedly [30, 31]. By the expulsion of contamination specialist, the sharpening to tuberculin is 
generally shorted and their action vanishes [32]. In a formerly tuberculin-negative crowd, the tuberculin positive creature is recognized amid calendar tuberculin testing interestingly and extraordinarily when the tuberculin -positive creature is youthful. Among ranch specialists, TB contamination ought to be viewed as [32]. The authenticity is the TB disease was brought about to homestead proprietor and it is firmly recommended that it was a probability of anthropozoonotic transmission of Mycobacterium tuberculosis contamination. Supporting information suggesting that human experiencing dynamic TB are the most plausible reason for Mycobacterium tuberculosis in domesticated animals have been depicted in the before period. The transmission of a Mycobacterium tuberculosis from human to dairy cattle their first clear proof was affirmed by IS6110 confinement section length polymorphism (RFLP) investigation was not reported until (2005) [33]. As of now PCR - based writing technique haas been presented e.g. MIRU-VNTR writing, that able speedier and more thorough strain separation. The Mycobacterium tuberculosis MIRU-VNTR writing framework comprises 15 loci, utilized as a part of this study, was recommended as the new standard for routine epidemiological separation of Mycobacterium tuberculosis segregates in 2006 [34]. an expansive number MIRU-VNTR utilized for genotyping Mycobacterium tuberculosis and Mycobacterium bovis segregates, it is best of our insight that working just two times to depict Mycobacterium tuberculosis secludes from animals $[35,36]$. Mycobacterium tuberculosis strains secluded in cows generally had a place with the Beijing and Beijing -like family [37] It is expressed that more TB cases happen in China (occurrence rate 96 for each 100,000 populace in 2009).

\section{CONCLUSION AND RECOMMENDATION}

The study finding gives vivacious measurements on the TB disease condition among patients of civil hospital New Darband population. TB is a highly common disease and major general medical issues concentrate on the ruler/urban population and extremely essential TB control programmers on a steady and study premise. Target programs must be initiated in prisons, particular high-hazard occupational groups, illegal medication clients, and people living in the street. Spread positive aspiratory cases, for the most part, happen in females, young age persons, and people having a place with poverty group. Early diagnosis and treatment are essential for TB control. For the incidence of TB poverty, poor cleanliness, absence of schooling, less viability of medications and besides poor pharmaceutical are the main elements. The TB control program must be lunched, appropriate health education, treatment centers, and well-trained practitioners and active health care persons are provided who provide guideline, awareness and educate the population.

\section{AUTHOR'S CONTRIBUTIONS}

Noorullah (NU) design the manuscript and arrange in appropriate sequence and also proof reading.

\section{ETHICS APPROVAL AND CONSENT TO PARTICIPATE}

Ethical approval was taken HOD Dr. Kashif Haleem head of ethical committee in the department of microbiology after explaining the cause and reason for research work. They official approve us to carryon study in hospital lab according to HEC curriculum.

\section{CONFLICT OF INTEREST}

Declared none.

\section{ACKNOWLEDGEMENTS}

Declared none.

\section{REFERENCES}

[1] Auletta S, Varani M, Horvat R, Galli F, Signore A, Hess S. PET radiopharmaceuticals for specific bacteria imaging: A systematic review. J Clin Med 2019; 8(2): 197.

DOI: $10.3390 / \mathrm{jcm} 8020197$

[2] Sasmita HY, Prasetyowati I, Wahjudi P. Prevalence and risk factors of diabetes mellitus in tuberculosis patient at Patrang district Indonesia. Indonesian J Trop Infect Dis 2019; 7(4): 79-85. DOI: $10.20473 /$ ijtid.v7i4.7534

[3] Khan MI, Khan JI, Ahmed SI, Ali S. The epidemiology of stroke In a developing country (Pakistan). Pak J Neurol Sci 2019; 13(3): 30-44.

[4] Machado P, Bizarro CV, Basso LA. Resistance reversed in KatG mutants of Mycobacterium tuberculosis. Trends Microbiol 2019; 27(8): 655-6.

DOI: $10.1016 /$ j.tim.2019.05.008

[5] Daley CL. The global fight against tuberculosis. Thoracic Surg Clin 2019; 29(1): 19-25. DOI: 10.1016/j.thorsurg.2018.09.010

[6] Kathleen M, Patrick B. Introduction to Thematic Issue Molecular Effectors of Tuberculosis Pathogenesis. USA: Oxford University Press 2019. DOI: 10.1093/femspd/fty077

[7] MacNeil A, Glaziou P, Sismanidis C, Maloney S, Floyd K. Global epidemiology of tuberculosis and progress toward achieving global targets-2017. MMWR 2019; 68(11): 263-66. DOI: $10.15585 / \mathrm{mmwr} . \mathrm{mm} 6811 \mathrm{a} 3$

[8] Al-Aarag AH, Omar MM, Mohammad AA, George MM. Tuberculosis situation in El-Minia governorate (1997-2010) before and after Direct Observed Therapy Short Course Strategy (DOTS). AJMPCP 2019; 2(1): 1-10.

[9] Patterson B, Wood R. Is cough really necessary for TB 
transmission? Tuberculosis (Edinburgh, Scotland) 2019; 117 : 31. DOI: $10.1016 / j$.tube.2019.05.003

[10] Khan A, Asghar A, Hashmi K, Farooq M, Shaheen B, Ali I. Mycobacterium tuberculosis: Pattern of First line drug resistance. APMC 2019; 13(1): 80-3.

[11] Yew WW, Leung CC, Chang KC, Zhang Y, Chan DP. Can treatment outcomes of latent TB infection and TB in silicosis be improved? J Thorac Dis 2019; 11(1): E8.

DOI: $10.21037 /$ jtd.2018.12.113

[12] Azeemuddin M, Alvi A, Sayani R, et al. Neuroimaging findings in tuberculosis: A single-center experience in 559 cases. J Neuroimaging 2019; 29(5): 657-68.

DOI: $10.1111 /$ jon. 12627

[13] Salindri AD, Auld SC, Schechter MC, Gandhi NR, Magee MJ. Negative tuberculin skin test result predicts all-cause mortality among tuberculosis patients with HIV and diabetes comorbidity. Ann Epidemiol 2019; 33: 72-8. e4.

DOI: 10.1016/j.annepidem.2019.02.005

[14] Amsalu E, Liu M, Li Q, et al. Spatial-temporal analysis of tuberculosis in the geriatric population of China: An analysis based on the Bayesian conditional autoregressive model. Arch Gerontol Geriatrics 2019; 83: 328-37.

DOI: 10.1016/j.archger.2019.05.011

[15] Mahmood MH. Prevalence of tuberculosis in Al-Falluja, Iraq 2012-2018. J Curr Med Res Opin 2019; 2(11): 343-6. DOI: $10.15520 /$ jcmro.v2i11.227

[16] Hussain H, Mori AT, Khan AJ, et al. The cost-effectiveness of incentive-based active case finding for tuberculosis (TB) control in the private sector Karachi, Pakistan. BMC Health Services Res 2019; 19(1): 690.

DOI: $10.1186 / \mathrm{s} 12913-019-4673-1$

[17] Reid M, Goosby E, Kevany S. Leveraging health diplomacy to end the tuberculosis epidemic. Lancet Global Health 2019; 7(5): e561-e2. DOI: 10.1016/S2214-109X(19)30058-0

[18] Panda S, Tiwari A, Luthra K, Sharma S, Singh A. Status of vitamin $\mathrm{D}$ and the associated host factors in pulmonary tuberculosis patients and their household contacts: A cross sectional study. J Steroid Biochem Mol Biol 2019; 193: 105419. DOI: 10.1016/j.jsbmb.2019.105419

[19] Qayyum AQA, Shafiq M, Farogh A. Prevalence of pulmonary tuberculosis among diabetics. Biomedica 2004; 20(02): 73-8.

[20] Khan JA, Irfan M, Zaki A, Beg M, Hussain SF, Rizvi N. Knowledge, attitude and misconceptions regarding tuberculosis in Pakistani patients. J Pak Med Assoc 2006; 56(5): 211.

[21] Alfonso C, Kokot W, Tölölyan K. Diaspora, Identity and Religion: New Directions in Theory And Research. Series: Routledge Research in Transnationalism. USA: CRC Press
2004; DOI: 10.4324/9780203401057

[22] Abdallah AM, Weerdenburg EM, Guan Q, et al. Integrated transcriptomic and proteomic analysis of pathogenic mycobacteria and their esx-1 mutants reveal secretion-dependent regulation of ESX-1 substrates and WhiB6 as a transcriptional regulator. PloS One 2019; 14(1): e0211003. DOI: 10.1371/journal.pone.0211003

[23] Tschopp R, Wassie L. Important role of Non tuberculous mycobacteria in non-human primate TB testing in Ethiopia. Ethiopian Vet J 2019; 23(2): 101-6. DOI: 10.4314/evj.v23i2.8

[24] Hill PC, Brookes RH, Fox A, et al. Surprisingly high specificity of the PPD skin test for M. tuberculosis infection from recent exposure in the Gambia. PLoS One 2006; 1(1): e68. DOI: 10.1371/journal.pone.0000068

[25] Mumtaz N, Chaudhry ZI, Mahmood N, Shakoori A. Reliability of PCR for detection of bovine tuberculosis in Pakistan. Pak J Zool 2008; 40(5).

[26] Collins D, Stephens D, De Lisle G. Comparison of polymerase chain reaction tests and faecal culture for detecting Mycobacterium paratuberculosis in bovine faeces. Vet Microbiol 1993; 36(3-4): 289-99.

DOI: 10.1016/0378-1135(93)90095-O

[27] Habitu T, Areda D, Muwonge A, Tessema GT, Skjerve E, Gebrehiwot T. Prevalence and risk factors analysis of bovine tuberculosis in cattle raised in mixed crop-livestock farming system in Tigray region, Ethiopia. Transbound Emerg Dis 2019; 66(1): 488-96. DOI: 10.1111/tbed.13050

[28] Duignan A, Kenny K, Bakker D, Good M. Tuberculin PPD Potency assays in naturally infected cattle as a quality control measure in the Irish Bovine tuberculosis eradication programme. Front Vet Sci 2019; 6: 328.

DOI: $10.3389 /$ fvets. 2019.00328

[29] Good M, Bakker D, Duignan A, Collins DM. The history of in vivo tuberculin testing in bovines: Tuberculosis, a "One Health" issue. Front Vet Sci 2018; 5: 59.

DOI: $10.3389 /$ fvets.2018.00059

[30] Toribio J-AL, Borja E, Borja LF, Prasad R, Tunabuna T. A retrospective study on bovine tuberculosis in cattle on Fiji: Study findings and stakeholder responses. Front Vet Sci 2018; 5: 270. DOI: $10.3389 /$ fvets. 2018.00270

[31] Guerra-Maupome M. Characterization of bovine unconventional memory-like responses induced by Mycobacterium bovis infection and vaccination. Abstract 2019; Available at: https://pdfs.semanticscholar.org/8415/7d7ce52f84713e3adb6 515412917613fa816.pdf?_ga=2.194566445.1251058677.157 6653551-1512152509.1534504459

[32] Fishman PS. Neurotransplantation. In: Gay WI, Heavner JE, Eds. Research Surgery and Care of the Research Animal: 
Surgical Approaches to the Organ Systems. USA: Elsevier 2016; p. 171. DOI: 10.1016/B978-0-12-278009-7.50010-8

[33] Ishag Z, Parsaeimehr A, Shao G-Q. Bovine Tuberculosis in the Republic of Sudan: A Critical Review. Tuberculosis in Animals: An African Perspective. USA: Springer 2019; pp. 403-13. DOI: 10.1007/978-3-030-18690-6_20

[34] Castagnolo D, Radi M, Dessì F, et al. Synthesis and biological evaluation of new enantiomerically pure azole derivatives as inhibitors of Mycobacterium tuberculosis. Bioorg Med Chem Lett 2009; 19(8): 2203-5.

DOI: $10.1016 / \mathrm{j} . \mathrm{bmcl} .2009 .02 .101$
[35] Yadav R, Naik R. Molecular structure, spectroscopic investigation (FT-IR, 1H NMR, 13C NMR and Mass) and quantum chemical calculations of Ruthenium (II) complex of isoniazid ligand. Indian J Pure Appl Phys 2019; 57: 118-31.

[36] Al-Sanjary R, Jwher DM. Direct detection of mycobacterium tuberculosis and mycobacterium bovis in cattle raw milk by using species-specific PCR technique. Assiut Vet Med J 2013; 59(136): 1-4.

[37] Takata A, Miyake N, et al. Integrative analyses of de novo mutations provide deeper biological insights into autism spectrum disorder. Cell Rep 2018; 22(3): 734-47. DOI: 10.1016/j.celrep.2017.12.074r 